\title{
Failure rates and complications of interspinous process decompression devices: a European multicenter study
}

\author{
Roberto Gazzeri, MD, ${ }^{1}$ Marcelo Galarza, MD, PhD, ${ }^{3}$ Massimiliano Neroni, MD, ${ }^{1}$ Claudio Fiore, MD, ${ }^{1}$ \\ Andrea Faiola, MD, ${ }^{1,5}$ Fabrizio Puzzilli, MD, ${ }^{2}$ Giorgio Callovini, MD, ${ }^{4}$ and Alex Alfieri, MD, $\mathrm{PhD}^{6}$ \\ 'Department of Neurosurgery, San Giovanni Addolorata Hospital; 2Department of Neurosurgery, "Sandro Pertini" Hospital; \\ ${ }^{4}$ Department of Neurosurgery, "Santo Spirito" Hospital; ${ }^{5}$ Department of Neurosurgery, San Filippo Neri Hospital, Rome, Italy; \\ ${ }^{3}$ Regional Service of Neurosurgery, "Virgen de la Arrixaca" University Hospital, Murcia, Spain; and ${ }^{\circ D e p a r t m e n t ~ o f ~ N e u r o s u r g e r y ~}$ \\ and Spinal Surgery, Ruppiner Kliniken, Neuruppin, Germany
}

OBJECT Spacers placed between the lumbar spinous processes represent a promising surgical treatment alternative for a variety of spinal pathologies. They provide an unloading distractive force to the stenotic motion segment, restoring foraminal height, and have the potential to relieve symptoms of degenerative disc disease. The authors performed a retrospective, multicenter nonrandomized study consisting of 1108 patients to evaluate implant survival and failure modes after the implantation of 8 different interspinous process devices (IPDs).

METHODS The medical records of patients who had undergone placement of an IPD were retrospectively evaluated, and demographic information, diagnosis, and preoperative pain levels were recorded. Preoperative and postoperative clinical assessments in the patients were based on the visual analog scale. A minimum of 3 years after IPD placement, information on long-term outcomes was obtained from additional follow-up or from patient medical and radiological records.

RESULTS One thousand one hundred eight patients affected by symptomatic 1- or 2-level segmental lumbar spine degenerative disease underwent placement of an IPD. The complication rate was $7.8 \%$. There were 27 fractures of the spinous process and 23 dura mater tears with CSF leakage. The ultimate failure rate requiring additional surgery was $9.6 \%$. The reasons for revision, which always involved removal of the original implant, were acute worsening of low-back pain or lack of improvement (45 cases), recurrence of symptoms after an initial good outcome (42 cases), and implant dislocation (20 cases).

CONCLUSIONS The IPD is not a substitute for a more invasive 3-column fusion procedure in cases of major instability and spondylolisthesis. Overdistraction, poor bone density, and poor patient selection may all be factors in the development of complications. Preoperatively, careful attention should be paid to bone density, appropriate implant size, and optimal patient selection.

http://thejns.org/doi/abs/10.3171/2015.7.FOCUS15244

KEY WORDS interspinous device; X-Stop; lumbar stenosis; degenerative disc disease; interspinous implant; herniated lumbar disc; complications spine surgery; spinous process fracture

\section{$\mathrm{L}$} UMBAR spinal stenosis due to degenerative changes is a disabling disease common in the elderly population, and several surgical and conservative treatment options have been proposed for its management. ${ }^{13,15,25,27,31,33,34,52}$ However, recent evidence suggests that surgery for degenerative lumbar spine stenosis achieves better results than nonsurgical care. ${ }^{31}$ Spinal decompression and fusion have been the standard treatment for spinal instability due to degenerative disc changes with subsequent central canal and neuroforaminal stenosis and for spondylolisthesis. Spacers placed between the lumbar spinous processes have become relatively common minimally invasive surgical treatment alternatives for a variety of spinal pathologies. ${ }^{6,8,11,14,21,30}$ They provide an unloading distractive force to the stenotic motion segment and have the potential to relieve symptoms of degenerative disc disease among patients who experience relief in spine flexion. ${ }^{2,37,41,48}$ Over the past several years, interspinous process spacers have provided alternatives to arthrodesis in older patients with degenerative lumbar disease. Several inter- 
spinous process devices (IPDs) have been introduced to the market and are currently available. ${ }^{16,26,24,28,29,31,39}$ They can be categorized as static or dynamic, and material compositions include titanium, polyetheretherketone (PEEK), and elastomeric compounds. 1,13,15,17,25,27,31,35,36,45 Surgical indications have been extended, ranging from degenerative spinal stenosis, discogenic low-back pain, facet syndrome, disc herniations, and low-grade instability. These devices are used either as "stand-alone" implants or to augment open decompression by preventing instability. One concern regarding this surgical technique is the relative structural weakness of the spinous processes: placement of an interspinous process spacer changes the mechanical role of the spinous process from a primary tension-bearing structure to a compression-loading one. However, the Food and Drug Administration investigational device exemption study for the X-Stop system (Medtronic) reported spinous process fractures as a relatively rare complication at the 2-year follow-up. ${ }^{51}$ But despite initial enthusiasm for the IPD as a safe, effective, and minimally invasive surgical alternative for the relief of neurological symptoms in patients with low-back degenerative disease, recent studies have demonstrated less impressive clinical results as well as a higher rate of failure than initial reports. We present our experience in a selected cohort of patients who underwent IPD insertion for various lumbar spine diseases. The aim of this study was to investigate the possible complications and failure rate associated with interspinous spacer placement.

\section{Methods}

The medical records of all patients who had undergone placement of an IPD for the treatment of degenerative lumbar spinal disease were retrospectively evaluated. All of these patients had symptoms of low-back pain, radiculopathy, and neurogenic claudication and were evaluated using MRI or CT studies of the lumbar spine. Only patients whose symptoms improved by bending forward were treated with IPD implantation alone or in combination with other surgical interventions (that is, microdiscectomy, foraminotomy, hemilaminectomy). Patients treated with IPD insertion in combination with interbody fusion (extreme lateral lumbar interbody fusion, posterior lumbar interbody fusion, and transforaminal lumbar interbody fusion) were excluded.

Demographic information, diagnosis, comorbidities, and preoperative pain levels were recorded. Preoperative and postoperative clinical assessments of the patients were based on the visual analog scale (VAS). A minimum of 3 years after IPD placement, information on long-term outcomes was obtained from additional follow-up or from patient medical and radiological records. Anteroposterior and/or lateral lumbar spine radiographs were evaluated to check the device position.

Patient satisfaction and postoperative pain outcomes were assessed using the rating scale of Finneson and Cooper, ${ }^{9}$ a lumbar disc surgery questionnaire that categorizes the postoperative assessment of patients into a 5-grade classification, from excellent to poor. Early postoperative and long-term follow-up complications were evaluated.
Revision surgeries such as IPD removal, laminectomy, and spinal fusion were recorded.

\section{Results}

Between January 2002 and January 2012, 1108 consecutive patients (593 men and 515 women) underwent placement of an IPD. Their mean age was 59 years (range 21-82 years; Table 1). Relevant medical history included hypertension (76 patients), chronic vascular disease (53 patients), diabetes (48 patients), asthma (24 patients), chronic lung disease (29 patients), and thyroid disease (25 patients). The most common pathology treated was lumbar stenosis (444), followed by herniated disc (223), minor instability associated or not with herniated disc (174 and 129 , respectively), and listhesis (31; Table 2).

The most common IPDs implanted were X-Stop, accounting for 422 cases, whereas DIAM insertion was performed in 193 cases and Viking implant in 185 patients. The operations were performed with the patient under general anesthesia in 950 cases and under local anesthesia in 158 cases.

In most cases (592 of 1108 patients), the L4-5 level was affected. The operation was performed at L3-4 in 138 patients and at L5-S1 in 229 patients; in 34 cases a device was implanted at the L2-3 level (Table 3). The interspinous spacer was implanted at 2 levels in 115 cases (Table 4).

The median operative time was 37 minutes (range 15-55 minutes) for the single level and 73 minutes (range 35-135 minutes) for the multiple levels, with an average blood loss of $48 \mathrm{ml}$ per procedure. No drainage was necessary at the implant site.

\section{Clinical Results}

The mean postoperative follow-up was 44.8 months (range 36-128 months). Estimation of survival over time was performed with a Kaplan-Meier analysis (Fig. 1).

Directly postoperatively, 13 patients experienced the persistence, early recurrence, or worsening of symptoms and thus underwent revision surgery in the 1st month after surgery. All patients with persistent or recurrent symptoms underwent postoperative MRI. Aside from 14 cases of acute low-back pain secondary to IPD malposition (with an oversized or undersized implant), other complications developed acutely as a result of surgery during the first 3 postoperative months: 23 patients experienced dura mater tears and CSF leakage after insertion of the dilator instrument in the interspinous space (18 cases at L5-S1 and 5 cases at L4-5 level). The CSF fistula was immediately treated with a muscular graft inserted in the hole and fibrin glue in all cases. In 12 cases subcutaneous CSF collection without clinical symptoms was noted after surgery and resolved with subcutaneous tapping in 7 cases and spontaneously in 5 patients. There were 27 intraoperative fractures of the spinous process: in these patients, the fractures were probably attributable to osteopenic bone and were caused by excessive force of the distractor instrument used to distract the ligaments and determine the adequate size of the implant. There were 16 cases of wound infection, which resolved with antibiotic therapy; 
TABLE 1. Clinical data on patients who underwent IPD insertion

\begin{tabular}{lccccccccc}
\hline \multicolumn{1}{c}{ Parameter } & DIAM & Coflex & Wallis & Viking & X-Stop & Ellipse & BacJac & Aperius & Total \\
\hline No. of cases & 193 & 15 & 27 & 185 & 422 & 58 & 141 & 67 & 1108 \\
\hline Mean age in yrs (range) & $45.5(21-65)$ & $59.4(48-64)$ & $57.4(45-66)$ & $56.3(35-79)$ & $65.1(51-82)$ & 57.2 & $58.7(35-77)$ & $72.5(63-80)$ & $59(21-82)$ \\
\hline Male/female & $108 / 85$ & $8 / 7$ & $12 / 15$ & $102 / 83$ & $227 / 195$ & $31 / 27$ & $77 / 64$ & $28 / 39$ & $593 / 515$ \\
\hline
\end{tabular}

in no case was deep infection noted. In only 13 cases did we radiologically note deep vein thrombosis of the lower limbs.

\section{Implant Survival Analysis}

Eight hundred forty-four patients $(76.2 \%)$ were very satisfied, $139(12.5 \%)$ were somewhat satisfied, and 125 $(11.3 \%)$ were not satisfied with the results of surgery after a minimum of 2 years of follow-up (Table 5).

In total, 107 patients had to undergo revision surgery during the long-term follow-up period. The presence of degenerative spondylolisthesis significantly increased the risk for reintervention (13 of 31 cases). The reasons for revision, which always consisted of removing the original implant, were acute worsening of low-back pain secondary to spinous fracture or overdistraction of the supraspinous ligament (27 cases), recurrence of symptoms after an initial good outcome (42 cases), total lack of improvement (18 cases), and implant dislocation (20 cases; Table 6).

In this study the overall reoperation rate was 9.6\%: 24 revision surgeries consisted of removing the interspinous spacer and decompressive surgery, 63 cases required additional instrumented fusion with pedicle screws (Table 7), 8 cases involved removal of the interspinous implant, and 12 cases required insertion of a new and bigger interspinous spacer.

When looking at the distribution of implant removal over time, we noted 2 stages: an early failure-stage (13 cases) within the first 3 months after surgery and another stage after a minimum of 2 years of follow-up (94 cases).

\section{Discussion}

Interspinous process devices have been introduced as a possible alternative to spinal decompression and arthrodesis for the treatment of neurogenic claudication and discogenic low-back pain. Over the past several years, IPDs have gained popularity for the treatment of degenerative lumbar diseases. 1,2,17,18,20,22,42 Recent clinical and radiological evidence has shown beneficial effects such as increased spinal canal and neural foramen dimensions with lowered intradiscal pressure at the level of the device and decreased pressure at the facets., ${ }^{2,37}$ The surgical approach can be performed after inducing local spinal anesthesia with short procedures and hospitalizations. Hence, this procedure has been proposed to an older, high-risk population for the treatment of a broad spectrum of lumbar spine degenerative diseases. In fact, the encouraging initial results of this minimally invasive technique for spinal stenosis have led to an expansion of its surgical indications for various painful lumbar conditions such as herniated disc disease, degenerative spondylolisthesis, and low-back pain and in young patients as well. ${ }^{12}$

Interspinous implants should theoretically prevent the development of the failed-back surgery syndrome by protecting the posterior spinal facet joints from overloading and restabilizing the intersegmental motion segment.

In the past years, we have seen a fairly increased number of young patients with degenerative disc disease, some with a severe type mainly related to their occupation. In young patients with huge disc herniations associated with microinstability, after microdiscectomy we implanted an IPD to prevent postoperative back pain and reduce the increased segmental flexion-extension and lateral bending motions observed after discectomy.

Previously reported complications associated with the use of interspinous spacers have included device dislocation or malposition, spinous process fractures, infection, hematoma, erosion of the spinous process, and neurological sequelae..$^{3,7}$

We performed a retrospective, multicenter nonrandomized study consisting of 1108 patients to evaluate implant survival and failure modes after the implantation of IPDs. In our study, we found a less favorable outcome than in other investigational studies. ${ }^{51,52}$ Revision rates after XStop implantation were $6 \%$ in Zucherman et al.'s investigation..$^{52}$ Although our indications were based on generally accepted criteria, we noted a high rate of reintervention $(9.6 \%)$, which is higher than the rates in the early literature. Part of the reason may be that our follow-up was substantially longer than that in other studies, which probably missed some late revisions. Another reason may be related to the implantation of oversized implants with overtension of the supraspinous ligament and higher compres-

TABLE 2. Spinal lumbar pathologies surgically treated

\begin{tabular}{lrrrrrrrrr}
\hline \multicolumn{1}{c}{ Pathology } & DIAM & Coflex & Wallis & Viking & X-Stop & Ellipse & BacJac & Aperius & Total \\
\hline Stenosis & 0 & 0 & 2 & 12 & 346 & 8 & 18 & 58 & 444 \\
\hline Stenosis \& herniated disc & 21 & 0 & 8 & 10 & 15 & 16 & 37 & 0 & 107 \\
\hline Minor instability \& black disc & 33 & 0 & 0 & 50 & 20 & 2 & 15 & 9 & 129 \\
\hline Minor instability \& herniated disc & 29 & 12 & 13 & 21 & 25 & 23 & 51 & 0 & 174 \\
\hline Herniated disc & 110 & 3 & 0 & 86 & 0 & 9 & 15 & 0 \\
\hline Listhesis Grade I & 0 & 0 & 4 & 6 & 16 & 0 & 5 & 0 \\
\hline
\end{tabular}


TABLE 3. Surgically treated single lumbar level in 993 cases

\begin{tabular}{cccccrrrrrr}
\hline Affected Level & DIAM & Coflex & Wallis & Viking & X-Stop & Ellipse & BacJac & Aperius & Total \\
\hline L2-3 & 5 & 0 & 1 & 5 & 21 & 0 & 2 & 0 & 34 \\
\hline L3-4 & 9 & 1 & 3 & 21 & 77 & 5 & 4 & 18 \\
\hline L4-5 & 94 & 13 & 17 & 85 & 248 & 29 & 79 & 27 & 592 \\
\hline L5-S1 & 70 & 1 & 0 & 57 & 43 & 14 & 34 & 10 & 229 \\
\hline
\end{tabular}

sion of the spinous process, whereas the under-tension of the ligamentum flavum with no improvement of pain and neurological signs may be secondary to undersized device implantation. Regardless, patient selection and surgical indication should be carefully considered.

In cases of late revision surgery, symptoms may recur late because of progressive narrowing of the spinal canal or subsidence of the implant with the loss of distraction. ${ }^{36}$ Early or late failures due to fractures of the spinal process were mechanical failures.

Reoperation rates for IPD range from $4.6 \%$ to as high as $85 \%$ in studies with long-term follow-up. $.7,10,19,32,45,47,49,51$ In our study, the overall reoperation rate was 9.6\%: We performed removal of the interspinous spacer and decompressive surgery in 24 patients, additional instrumented fusion with pedicle screws in 63 cases, removal of the interspinous spacer only in 8 cases, and insertion of a new interspinous implant in 12 cases. We removed the IPD with no further spinal fixation or decompression in older patients with multiple comorbidities in whom major spinal surgery could have been life threatening.

Data in the current study suggest that IPDs with a long follow-up may be associated with a higher rate of complications than previously reported.

Although the implantation of interspinous spacers is considered a less invasive procedure than the classic lumbar laminectomy for the treatment of lumbar spinal stenosis due to degenerative changes, our results showed that it is not an entirely benign operation, unless a careful analysis of the patient's indications is performed.

One of those interspinous spacers is the X-Stop device, which has shown efficacy as compared with conservative treatment. ${ }^{3,52}$ Although most published data show a stable clinical success rate over time, ${ }^{51,52}$ there are some reports of a less favorable outcome after an initial short-term improvement. ${ }^{38}$ Bowers et al. showed a long-term complication rate of $38 \%$, with $11(85 \%)$ of 13 patients requiring additional spine surgery after X-Stop placement. ${ }^{5}$ These authors observed a higher rate of spinous process fracture (23\%) than previously reported.

In a retrospective study done by Tuschel et al., a fairly high revision rate $(30.4 \%)$ was observed. ${ }^{45}$ Fourteen cases had to undergo revision surgery due to worsening pain within the first 12 months in 11 cases, implant dislocation in 2 patients, and fracture of the spinous process in 1 case. In 1 case, spacer dislocation was secondary to trauma from a skiing accident.

Verhoof et al. reported an extremely high failure rate for X-Stop interspinous distraction, defined by a requirement for surgical reintervention, in patients with lumbar spinal stenosis caused by degenerative spondylolisthesis with an average percentage of slip less than $25 \% .{ }^{47} \mathrm{Sec}$ ondary surgery was required in $7(58 \%)$ of 12 patients within 24 months. In another study, 42 patients with spinal stenosis secondary to lumbar degenerative spondylolisthesis and treated with X-Stop were compared with 33 patients who received nonoperative treatment. ${ }^{3}$ Although the overall clinical success rate of $63.4 \%$ was achieved in the $\mathrm{X}$-Stop group compared with $12.9 \%$ in the control group at 2 years of follow-up, surgical reintervention was required in $5(11.9 \%)$ patients in the X-Stop group compared with $12.1 \%$ in the control group. In another study, since $80 \%$ of patients with Grade I spondylolisthesis required additional surgery after IPD placement, the authors supported the recommendation not to use X-Stop in patients with spondylolisthesis. ${ }^{5}$

Stucki et al. reported 2-year outcomes in 197 patients with neurogenic intermittent claudication treated with lumbar laminectomy versus X-Stop-treated patients, demonstrating higher Zurich Claudication Questionnaire success rates than the scores for laminectomy patients. ${ }^{40}$ Turner and colleagues evaluated the cost-effectiveness of $\mathrm{X}$-Stop and laminectomy surgery during the index hospitalization for the treatment of 33 patients with lumbar spinal stenosis in the US. ${ }^{44}$ Patients were matched for age, number of levels treated, and preoperative disability. XStop was shown to be significantly more cost-effective than laminectomy for the treatment of 1- and 2-level lumbar spinal stenosis. Furthermore, because there were no surgical complications in the IPD group with a shorter operative time as compared with the open decompression group, the authors suggested that this surgery may be preferred in older, destabilized patients with comorbidities.

Decompressive surgery with or without fusion is the

TABLE 4. Multiple lumbar levels surgically treated in 115 cases

\begin{tabular}{ccccccrrrrr}
\hline Affected Level & DIAM & Coflex & Wallis & Viking & X-Stop & Ellipse & BacJac & Aperius & Total \\
\hline L1-3 & 0 & 0 & 0 & 0 & 1 & 0 & 0 & 0 \\
\hline L2-4 & 4 & 0 & 2 & 3 & 3 & 0 & 2 & 0 \\
\hline L2-5 & 0 & 0 & 1 & 0 & 1 & 0 & 0 & 0 \\
\hline L3-5 & 3 & 0 & 3 & 10 & 16 & 3 & 4 & 6 \\
\hline L4-S1 & 8 & 0 & 0 & 4 & 12 & 7 & 16 & 6 \\
\hline
\end{tabular}




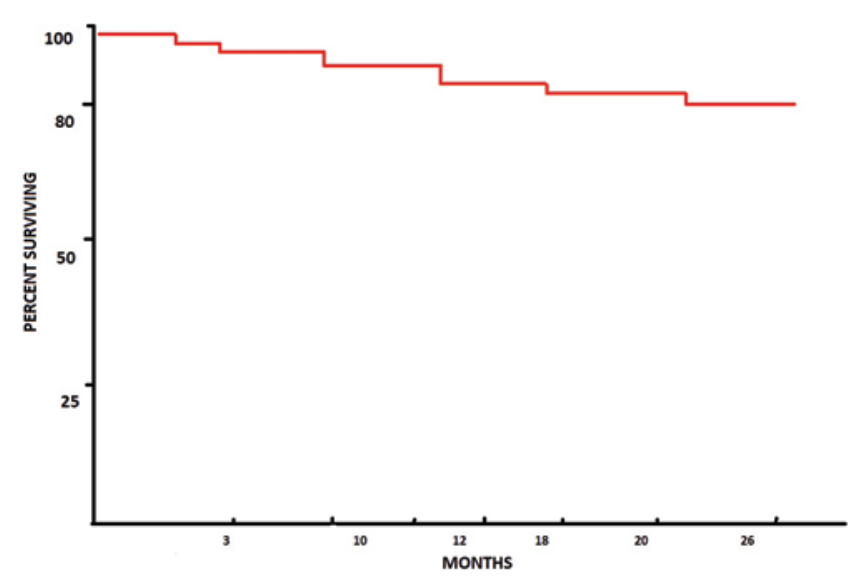

FIG. 1. Estimation of patient survival over time performed with a KaplanMeier analysis.

current "gold standard" treatment for symptomatic lumbar spinal stenosis of moderate to severe grade. Decompressive surgery provides good clinical outcomes, improving a patient's quality of life. Nevertheless, decompressive surgery may be associated with major complications, particularly in cases in which fusion is also performed. Postoperative complications may include cardiovascular and pulmonary complications, infection, iatrogenic instability, pseudarthrosis, hardware failure, and/or the need for repeat surgery for the occurrence of new disease at the same or adjacent levels. In 1992, an extensive meta-analysis of the literature on spinal stenosis surgery by Turner et al. revealed the following complication rates for lumbar decompressive surgery: perioperative mortality $0.3 \%$, dural tears $5.9 \%$, deep infection $1.1 \%$, superficial infection $2.3 \%$, and deep vein thrombosis $2.8 \%$, for an overall complication rate of $12.6 \% .{ }^{44}$ The overall complication rate in X-Stop surgery was $3.3 \%$, including fracture of the spinous processes, dislocation of the prosthesis, and skin infections, whereas the rate for decompressive laminectomies was $9.7 \% .{ }^{44}$ Moreover, the decision to reoperate because of a lack of clinical improvement or the worsening of neurological symptoms is more easily taken after a less invasive procedure like interspinous device implantation than after open decompression of the spinal canal.

In our study, 20 patients experienced IPD dislocation with supraspinous ligament rupture. Interspinous process device dislocation may be attributed to the V-shaped appearance of the posterior interspinous spaces or may be secondary to accidental falls. In the study by Barbagallo et al., 4 patients experienced postoperative device dislocations, and in all cases revision surgery was required. Instrumented fusion was performed in 1 case, whereas removal of the dislocated device alone was performed in the other patients because they did not consent to any further surgery. In all 4 cases, the supraspinous ligament was ruptured. 4

Few studies have reported the malposition of an IPD even when intraoperative radiographic guidance was used. Zhang et al. noted malpositioning of the Coflex device in 1 case, while Anderson et al. found 1 case of X-Stop malposition after postoperatively reviewing radiographic images in 191 cases. $^{3,50}$ Although the IPD should be implanted deeply in the interspinous space, close to the zygapophysial joints, this correct position may be difficult to achieve in older patients with hypertrophy of the joints and pronounced osteophytes. In many of our cases, dislocation of the device occurred at the L5-S1 level, which is more difficult anatomically given a smaller $\mathrm{S}-1$ spinous process.

Malpositioning of an IPD may be more frequent if the device is implanted percutaneously. In a prospective multicenter study on the safety and effectiveness of the Aperius IPD, $14(9 \%)$ patients had their device removed during the 12-month postprocedural period because of persistent or recurring symptoms (10 cases), spinous process fracture (3 cases), or malpositioning ( 1 case). ${ }^{46}$ In our study, 67 devices were implanted percutaneously. Of these, 3 were removed because of malpositioning, 1 because of spinous fracture, and 5 because of neurological worsening. In 4 cases with worsening or recurrent pain, conservative treatment was performed.

Normally, the spinous process is under tension from the interspinous ligament. But after placement of an IPD, this tension is altered, with higher compression of the spinous process. This pressure can lead to fracture of the spinous process. The incidence and clinical significance of spinous process fracture after IPD placement have yet to be clarified. One concern is the frequency of spinous process fractures documented on $\mathrm{CT}$ but missed on radiography. Postoperative spinous process fractures have been reported in $1 \%-5.8 \%$ of patients after plain radiographic spinal evaluation, but most fractures occur in the area between the base and the midportion of the spinous process, which is difficult to identify on radiography because of the spacer design and the osteopenic bone and metal in IPD spacers that can obscure the fracture. In a series of 38 patients treated with titanium or PEEK X-Stop and Lanx devices, the frequency of spinous fractures was $22 \%$ (11 patients), but only 5 patients with fracture were symp-

TABLE 5. Summary of clinical outcomes at a minimum of 24 months of follow-up, according to the rating scale of Finneson and Cooper

\begin{tabular}{|c|c|c|c|c|c|c|c|c|c|c|}
\hline Rating & Definition & DIAM & Coflex & Wallis & Viking & X-Stop & Ellipse & BacJac & Aperius & Total \\
\hline Excellent & Pain free \& able to function well & 91 & 8 & 9 & 81 & 185 & 16 & 57 & 13 & 460 \\
\hline Good & Pain improved \& able to function well & 74 & 5 & 7 & 74 & 129 & 24 & 43 & 28 & 384 \\
\hline Fair & $\begin{array}{l}\text { Pain improved, but occasional medication \& time off from activ- } \\
\text { ities }\end{array}$ & 13 & 1 & 6 & 13 & 60 & 15 & 20 & 11 & 139 \\
\hline Marginal & $\begin{array}{l}\text { Pain improved, but considerable discomfort that requires fre- } \\
\text { quent medication \& time off from activities }\end{array}$ & 7 & 1 & 2 & 11 & 30 & 2 & 12 & 8 & 73 \\
\hline Poor & Pain unimproved or worse & 8 & 0 & 3 & 6 & 18 & 1 & 9 & 7 & 52 \\
\hline
\end{tabular}


TABLE 6. Overview of complications and failures in patients who underwent IPD implantation at our hospitals

\begin{tabular}{llllllllcc}
\hline \multicolumn{1}{c}{ Outcome } & DIAM & Coflex & Wallis & Viking & X-Stop & Ellipse & BacJac & Aperius & Total \\
\hline Dislocation & 0 & 1 & 0 & 0 & 15 & 0 & 2 & 2 & 20 \\
\hline Fracture & 2 & 0 & 1 & 5 & 16 & 1 & 1 & 1 & 27 \\
\hline Malposition (over/under distraction) & 3 & 0 & 0 & 3 & 0 & 0 & 5 & 3 & 14 \\
\hline Instability & 0 & 0 & 0 & & 0 & 0 & 3 & 0 & 3 \\
\hline Infection & 0 & 0 & 0 & & 0 & 0 & 0 & 0 & 0 \\
\hline CSF leakage & 5 & 1 & 0 & 3 & 9 & 3 & 2 & 0 & 23 \\
\hline No improvement/worsening of pain & 3 & 0 & 0 & 7 & 0 & 2 & 5 & 3 \\
\hline Recurrent pain & 9 & 0 & 3 & 6 & 24 & 2 & 7 & 6 \\
\hline Total no. (\%) & $22(11.3)$ & $2(13.3)$ & $4(14.8)$ & $24(12.9)$ & $64(15.1)$ & $8(13.8)$ & $25(17.7)$ & $15(22.3)$ & $164(14.8)$ \\
\hline
\end{tabular}

tomatic, and just 3 required device removal and posterior decompression. ${ }^{18}$ No fracture was visualized on plain radiographs, although in most cases it could be identified using thin-cut CT sagittal reformatted images. Barbagallo et al. described 69 cases in which an X-Stop device was implanted, and the main complications were spinous process fracture and implant displacement, with an incidence rate of $11.6 \%$. In that study, 4 patients had spinous process fracture (1 intraoperatively, 3 postoperatively); the authors suggested that repetitive motion between $2 \mathrm{X}$-Stop devices may have caused excessive force resulting in a spinous process fatigue fracture. ${ }^{4}$ In the study described by Zang et al., the complications included 5 spinous process fractures, associated with Coflex dislodgment in 1 case, for a complication incidence rate of $9.8 \% .^{50}$

In our study, the reasons for the spinous process fractures were unknown, although possible factors include the patient's degree of osteoporosis and possible overdistraction of the interspinous space with a large interspinous device. Among our patients, 27 had a spinous process fracture (18 in the early postoperative period and 9 after 1 year postsurgery), which was symptomatic in 22. The IPD was removed in 22 cases. One patient experienced painful spontaneous spinal process fracture without any history of trauma or strenuous activity, after 4 years of follow-up, suggesting a possible fatigue fracture. Although reporting a VAS score of 8 , the patient refused any further surgery. We suggest carefully evaluating the bone density of each patient preoperatively and considering whether a modest distraction and adequately sized device are needed to avoid spinous process fractures, especially in osteopenic/ osteoporotic patients (Figs. 2-4).

Tian et al. investigated the incidence rate of heterotopic ossification after implantation of Coflex interspinous devices. Among a total of 32 cases, heterotopic ossification was detected in $81.2 \%$ (26 cases). In 8 patients, ossifica- tion occurred in the lateral space of the spinous process. In 16 patients, ossification occurred in the interspinous space but did not bridge the adjacent spinous processes, whereas interspinous fusion occurred in 2 patients. ${ }^{43}$ None of the patients experienced a recurrence of symptoms resulting from the ossification. The significance of heterotopic ossification after IPD insertion is still unclear; large osteophytes could intrude into the spinal canal, compressing the dural sac. However, this outcome is very rare, with only 1 case reported. In the case described by Maida et al., neural structures were compressed by heterotopic bone, resulting in the recurrence of spinal stenosis symptoms. ${ }^{23}$ Theoretically, interspinous ossification is not necessarily bad because it could enhance stabilization at the treated level.

Furthermore, in the last few years, new interspinous fusion devices have been used as an alternative to pedicle screws in achieving fusion (interspinous ossification) to treat degenerative lumbar instability or instability caused by decompressive lumbar surgery. ${ }^{13}$

We observed that patients with X-Stop and Aperius devices were older than patients treated with other devices. In these cases, we suggest that poor bone quality may have resulted in a higher incidence of spinous fracture than in younger patients.

In our cohort of 1108 patients, there were 23 cases $(1.8 \%)$ of dura mater tears and CSF leaks after insertion of the dilator instrument in the interspinous space. In 18 cases the CSF fistula occurred at L5-S1 and in 5 cases at the L4-5 level. In all cases the leakage was immediately treated with a muscular graft inserted in the hole and fibrin glue. The dura mater tear occurred especially at the L5-S1 level, where the dural sac is anatomically located more posteriorly, probably secondary to a low insertion of the dilator instrument. To avoid this complication, a more superficial position of the device, in the midportion of the interspinous ligament of L5-S1, should be achieved.

TABLE 7. Revision surgery after IPD implantation

\begin{tabular}{lccccccccc}
\hline \multicolumn{1}{c}{ Surgery } & DIAM & Coflex & Wallis & Viking & X-Stop & Ellipse & BacJac & Aperius & Total \\
\hline Instrumented fusion & 1 & 0 & 0 & 2 & 15 & 1 & 5 & 4 & 28 \\
\hline Laminectomy \& instrumented fusion & 3 & 0 & 2 & 3 & 21 & 2 & 4 & 0 & 35 \\
\hline Laminectomy & 6 & 0 & 1 & 2 & 11 & 0 & 2 & 2 & 24 \\
\hline IPD removal & 1 & 1 & 0 & 0 & 3 & 0 & 2 & 1 & 8 \\
\hline New IPD & 4 & 0 & 0 & 2 & 0 & 0 & 3 & 3 \\
\hline
\end{tabular}




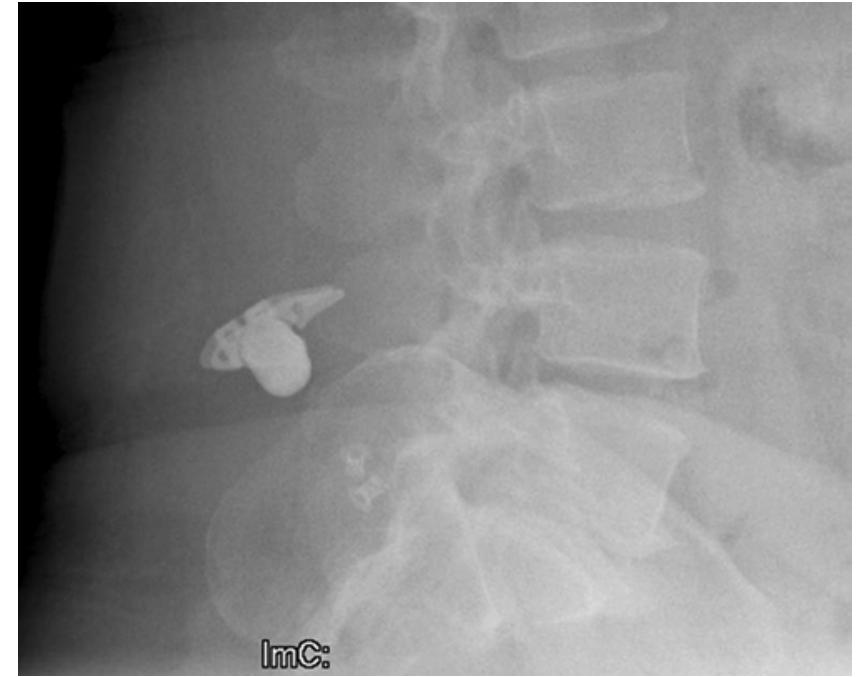

FIG. 2. Image obtained in a 68-year-old man who returned for acute back pain 3 years after IPD surgery. The lumbar spinal radiograph shows posterior migration of the X-Stop device.

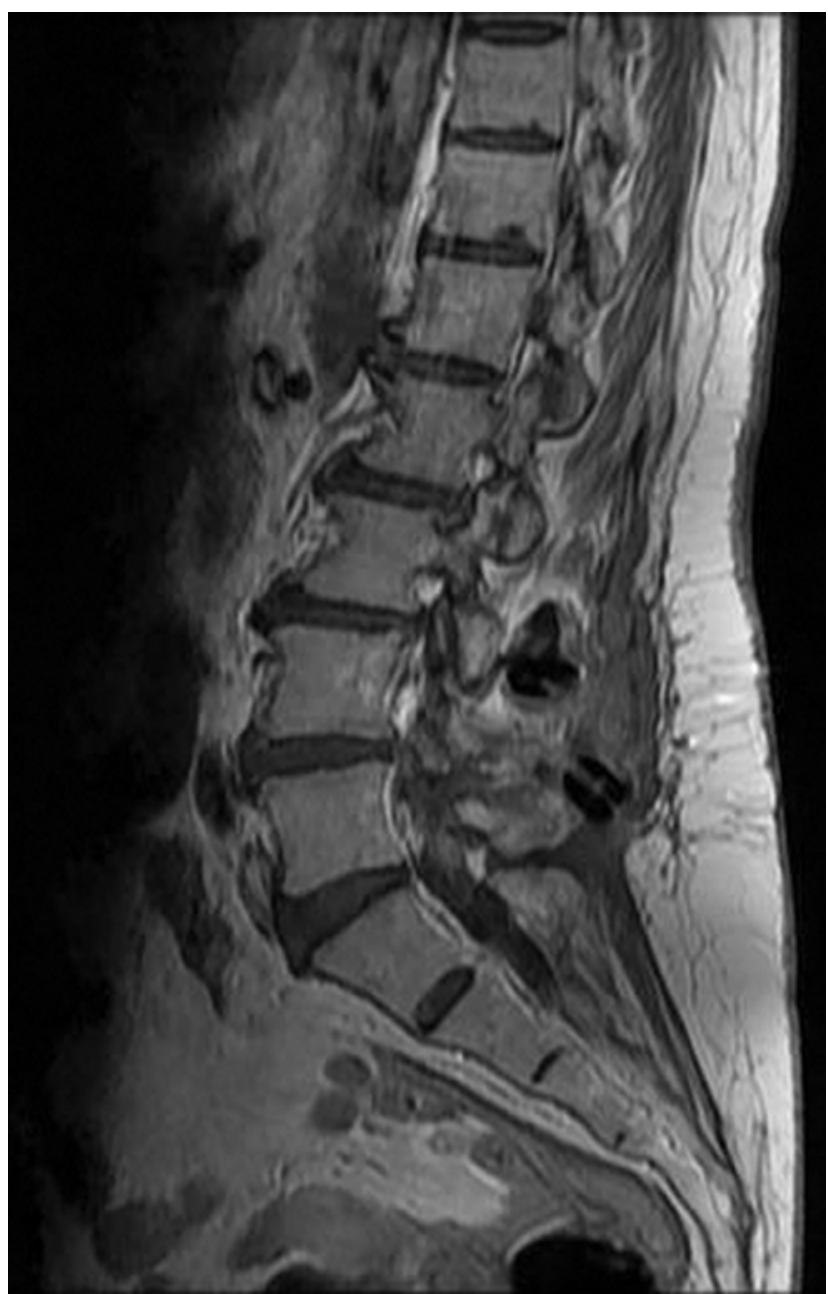

FIG. 3. Two interspinous devices (BacJac) were implanted at L3-5 in a 58-year-old woman. Two years after surgery she complained of back pain and worsening of her neurological symptoms. The spinal MR image shows migration of the radiotransparent IPD implanted at the L4-5 interspinous level.

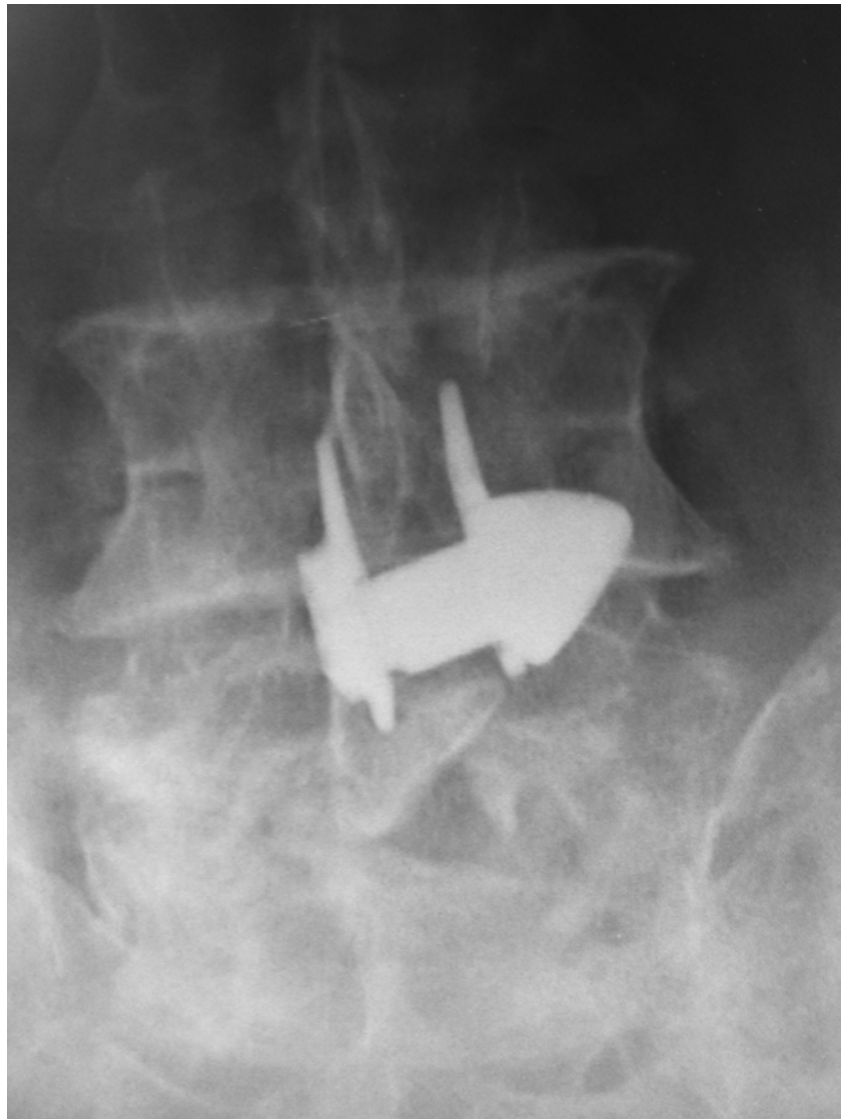

FIG. 4. A patient experienced a spontaneous painful spinal process fracture, without any history of trauma or strenuous activity, after 4 years of follow-up. Although reporting a VAS score of 8 , the patient refused any further surgery.

Infection risk using an IPD is reduced, although on postoperative MRI we observed a fluid serous collection around the silicone implant (DIAM) in a series of our patients. This was not specifically associated with other clinical conditions, such as fever and infection, and we suggest that it could be related to a temporary host-foreign material reaction.

Our study has several limitations. It is a retrospective study with a follow-up that is not the same among the patients. Moreover, patient age and treated pathology differ from one implant to another. The radiological follow-up is another limitation. Although CT scanning is a more accurate method of detecting fractures of the spinal process, in our study the majority of patients underwent spinal radiography. Another weakness was the absence of a costeffectiveness comparison between IPDs and other surgical approaches for the treatment of lumbar spinal diseases, although that was not the purpose of our study. Such a comparison would have required a different study proto$\mathrm{col}$, one reflecting a variety of complex financial and international issues such as cost reimbursement in the different participating countries.

The perceived advantages of IPD implantation are that it is less invasive than laminectomy, it does not involve destabilizing removal of posterior vertebral elements, and it is reversible. 


\section{Conclusions}

Evidence-based spine trials for IPD are not enough. Indeed, better scientific grounding is needed among spine surgeons when using these devices. We still do not know in which cases the use of an IPD would be considered the gold standard. These devices have numerous indications, including lumbar canal stenosis, degenerative spondylolisthesis (Grade I), discogenic low-back pain, facet syndrome, and lumbar disc herniation, and appropriate application is required for devices with such widespread utility. In our opinion, IPD should be considered a surgical option for patients with comorbidities and a high risk for postoperative complications. Younger patients who can tolerate a more invasive procedure can undergo laminectomy and posterior fixation.

\section{References}

1. Adelt D: [The interspinous U implant (now Coflex): longterm outcome, study overview and differential indication.] Orthopade 39:595-601, 2010.(Ger)

2. Alfieri A, Gazzeri R, Prell J, Scheller C, Rachinger J, Strauss $\mathrm{C}$, et al: Role of lumbar interspinous distraction on the neural elements. Neurosurg Rev 35:477-484, 2012

3. Anderson PA, Tribus CB, Kitchel SH, Hartjen CA: Treatment of neurogenic claudication by interspinous decompression: application of the X STOP device in patients with lumbar degenerative spondylolisthesis. J Neurosurg Spine 4:463-471, 2006

4. Barbagallo GM, Olindo G, Corbino L, Albanese V: Analysis of complications in patients treated with the X-Stop Interspinous Process Decompression System: proposal for a novel anatomic scoring system for patient selection and review of the literature. Neurosurgery 65:111-120, 2009

5. Bowers C, Amini A, Dailey AT, Schmidt MH: Dynamic interspinous process stabilization: review of complications associated with the X-Stop device. Neurosurg Focus 28(6):E8, 2010

6. Brussee P, Hauth J, Donk RD, Verbeek ALM, Bartels RHM: Self-rated evaluation of outcome of the implantation of interspinous process distraction (X-Stop) for neurogenic claudication. Eur Spine J 17:200-203, 2008

7. Epstein NE: A review of interspinous fusion devices: High complication, reoperation rates, and costs with poor outcomes. Surg Neurol Int 3:7, 2012

8. Fabrizi AP, Maina R, Schiabello L: Interspinous spacers in the treatment of degenerative lumbar spinal disease: our experience with DIAM and Aperius devices. Eur Spine J 20 (Suppl 1):S20-S26, 2011

9. Finneson BE, Cooper VR: A lumbar disc surgery predictive score card. A retrospective evaluation. Spine (Phila Pa 1976) 4:141-144, 1979

10. Floman Y, Millgram MA, Smorgick Y, Rand N, Ashkenazi E: Failure of the Wallis interspinous implant to lower the incidence of recurrent lumbar disc herniations in patients undergoing primary disc excision. J Spinal Disord Tech 20:337-341, 2007

11. Galarza M, Fabrizi AP, Maina R, Gazzeri R, Martínez-Lage JF: Degenerative lumbar spinal stenosis with neurogenic intermittent claudication and treatment with the Aperius PercLID System: a preliminary report. Neurosurg Focus 28(6):E3, 2010

12. Galarza M, Gazzeri R, De la Rosa P, Martínez-Lage JF: Microdiscectomy with and without insertion of interspinous device for herniated disc at the L5-S1 level. J Clin Neurosci 21:1934-1939, 2014

13. Gazzeri R, Galarza M, Alfieri A: Controversies about inter- spinous process devices in the treatment of degenerative lumbar spine diseases: past, present, and future. BioMed Res Int 2014:975052, 2014

14. Goyal A, Goel VK, Mehta A, Dick D, Chinthakunta SR, Ferrara L: Cyclic loads do not compromise functionality of the interspinous spacer or cause damage to the spinal segment: an in vitro analysis. J Long Term Eff Med Implants 18:289-302, 2008

15. Hsu KY, Zucherman JF, Hartjen CA, Mehalic TF, Implicito DA, Martin MJ, et al: Quality of life of lumbar stenosis-treated patients in whom the X STOP interspinous device was implanted. J Neurosurg Spine (Phila Pa 1976) 5:500-507, 2006

16. Idler C, Zucherman JF, Yerby S, Hsu KY, Hannibal M, Kondrashov D: A novel technique of intra-spinous process injection of PMMA to augment the strength of an inter-spinous process device such as the X STOP. Spine (Phila Pa 1976) 33:452-456, 2008

17. Kim DH, Albert TJ: Interspinous process spacers. J Am Acad Orthop Surg 15:200-207, 2007

18. Kim KA, McDional M, Pik JHT, Khoueir P: Dynamic intraspinous spacer technology for posterior stabilization: clinical safety, sagittal angulation, and pain outcome at 1-year followup evaluation. Neurosurg Focus 22(1):E7, 2007

19. Kondrashov DG, Hannibal M, Hsu KY, Zucherman JF: Interspinous process decompression with the X-STOP device for lumbar spinal stenosis: a 4-year follow-up study. J Spinal Disord Tech 19:323-327, 2006

20. Kong DS, Kim ES, Eoh W: One-year outcome evaluation after interspinous implantation for degenerative spinal stenosis with segmental instability. J Korean Med Sci 22:330-335, 2007

21. Lauryssen C: Appropriate selection of patients with lumbar spinal stenosis for interspinous process decompression with the X STOP device. Neurosurg Focus 22(1):E5, 2007

22. Lindsey DP, Swanson KE, Fuchs P, Hsu KY, Zucherman JF, Yerby SA: The effects of an interspinous implant on the kinematics of the instrumented and adjacent levels in the lumbar spine. Spine (Phila Pa 1976) 28:2192-2197, 2003

23. Maida G, Marcati E, Sarubbo S: Heterotopic ossification in vertebral interlaminar/interspinous instrumentation: report of a case. Case Rep Surg 2012:970642, 2012

24. Mariottini A, Pieri S, Giachi S, Carangelo B, Zalaffi A, Muzii FV, et al: Preliminary results of a soft novel lumbar intervertebral prothesis (DIAM) in the degenerative spinal pathology. Acta Neurochir Suppl 92:129-131, 2005

25. Mayer HM: Microsurgical decompression for acquired (degenerative) central and lateral spinal canal stenosis, in Mayer HM (ed): Minimally Invasive Spine Surgery, ed 2. Berlin: Springer, 2006

26. Mayer HM, Zentz F, Siepe C, Korge A: [Percutaneous interspinous distraction for the treatment of dynamic lumbar spinal stenosis and low back pain.] Oper Orthop Traumatol 22:495-511, 2010 (Ger)

27. McCulloch A: Microsurgery for lumbar spinal canal stenosis, in McCulloch JA, Young PH, (eds): Essentials of Spinal Microsurgery. Philadelphia: Lippincott-Raven, 1998

28. Miller LE, Block JE: Interspinous spacer implant in patients with lumbar spinal stenosis: preliminary results of a multicenter, randomized, controlled trial. Pain Res Treat 2012:823509, 2012

29. Neroni M, Gazzeri R, Conforti G, Visocchi M: State of art of recurrent lumbar disk herniation, interspinous and interlumbar fusions. J Neurosurg Sci 58 (2 Suppl 1):45-48, 2014

30. Park SW, Lim TJ, Park J: A biomechanical study of the instrumented and adjacent lumbar levels after In-Space interspinous spacer insertion. J Neurosurg Spine 12:560-569, 2010

31. Phillips FM, Voronov LI, Gaitanis IN, Carandang G, Havey 
RM, Patwardhan AG: Biomechanics of posterior dynamic stabilizing device (DIAM) after facetectomy and discectomy. Spine J 6:714-722, 2006

32. Puzzilli F, Gazzeri R, Galarza M, Neroni M, Panagiotopoulos K, Bolognini A, et al: Interspinous spacer decompression (X-STOP) for lumbar spinal stenosis and degenerative disk disease: a multicenter study with a minimum 3-year followup. Clin Neurol Neurosurg 124:166-174, 2014

33. Richards JC, Majumdar S, Lindsey DP, Beaupré GS, Yerby SA: The treatment mechanism of an interspinous process implant for lumbar neurogenic intermittent claudication. Spine (Phila Pa 1976) 30:744-749, 2005

34. Schmoelz W, Huber JF, Nydegger T, Claes L, Wilke HJ: Dynamic stabilization of the lumbar spine and its effecrs on adjacent segments: an in vitro experiment. J Spinal Disord Tech 16:418-423, 2003

35. Sénégas J: Mechanical supplementation by non-rigid fixation in degenerative intervertebral lumbar segments: the Wallis system. Eur Spine J 11 (Suppl 2):S164-S169, 2002

36. Sénégas J, Vital JM, Pointillart V, Mangione P: Long-term actuarial survivorship analysis of an interspinous stabilization system. Eur Spine J 16:1279-1287, 2007

37. Siddiqui M, Karadimas E, Nicol M, Smith FW, Wardlaw D: Effects of X-STOP device on sagittal lumbar spine kinematics in spinal stenosis. J Spinal Disord Tech 19:328-333, 2006

38. Siddiqui M, Karadimas E, Nicol M, Smith FW, Wardlaw D: Influence of X Stop on neural foramina and spinal canal area in spinal stenosis. Spine (Phila Pa 1976) 31:2958-2962, 2006

39. Siddiqui M, Nicol M, Karadimas E, Smith F, Wardlaw D: The positional magnetic resonance imaging changes in the lumbar spine following insertion of a novel interspinous process distraction device. Spine (Phila Pa 1976) 30:26772682,2005

40. Stucki G, Daltroy L, Liang MH, Lipson SJ, Fossel AH, Katz $\mathrm{JN}$ : Measurement properties of a self-administered outcome measure in lumbar spinal stenosis. Spine (Phila Pa 1976) 21:796-803, 1996

41. Swanson KE, Lindsey DP, Hsu KY, Zucherman JF, Yerby SA: The effects of an interspinous implant on intervertebral disc pressures. Spine (Phila Pa 1976) 28:26-32, 2003

42. Taylor J, Pupin P, Delajoux S, Palmer S: Device for intervertebral assisted motion: technique and initial results. Neurosurg Focus 22(1):E6, 2007

43. Tian NF, Wu AM, Wu LJ, Wu XL, Wu YS, Zhang XL, et al: Incidence of heterotopic ossification after implantation of interspinous process devices. Neurosurg Focus 35(2):E3, 2013

44. Turner JA, Ersek M, Herron L, Deyo R: Surgery for lumbar spinal stenosis. Attempted meta-analysis of the literature. Spine (Phila Pa 1976) 17:1-8, 1992

45. Tuschel A, Chavanne A, Eder C, Meissl M, Becker P, Ogon M: Implant survival analysis and failure modes of the $\mathrm{X}$ -
Stop interspinous distraction device. Spine (Phila Pa 1976) 38:1826-1831, 2013

46. Van Meirhaeghe J, Fransen P, Morelli D, Craig NJ, Godde $\mathrm{G}$, Mihalyi A, et al: Clinical evaluation of the preliminary safety and effectiveness of a minimally invasive interspinous process device APERIUS ${ }^{\circledR}$ in degenerative lumbar spinal stenosis with symptomatic neurogenic intermittent claudication. Eur Spine J 21:2565-2572, 2012

47. Verhoof OJ, Bron JL, Wapstra FH, van Royen BJ: High failure rate of the interspinous distraction device (X-Stop) for the treatment of lumbar spinal stenosis caused by degenerative spondylolisthesis. Eur Spine J 17:188-192, 2008

48. Wiseman CM, Lindsey DP, Fredrick AD, Yerby SA: The effect of an interspinous process implant on facet loading during extension. Spine (Phila Pa 1976) 30:903-907, 2005

49. Xu C, Ni WF, Tian NF, Hu XQ, Li F, Xu HZ: Complications in degenerative lumbar disease treated with a dynamic interspinous spacer (Coflex). Int Orthop 37:2199-2204, 2013

50. Zang L, Du P, Hai Y, Su QJ, Lu SB, Liu T: Device related complications of the Coflex interspinous process implant for the lumbar spine. Chin Med J (Engl) 126:2517-2522, 2013

51. Zucherman JF, Hsu KY, Hartjen CA, Mehalic TF, Implicito DA, Martin MJ, et al: A multicenter, prospective, randomized controlled trial evaluating the X STOP interspinous process decompression system for the treatment of neurogenic intermittent claudication: two-year follow-up results. Spine (Phila Pa 1976) 30:1351-1358, 2005

52. Zucherman JF, Hsu KY, Hartjen CA, Mehalic TF, Implicito DA, Martin MJ, et al: A prospective randomized multi-center study for the treatment of lumbar spinal stenosis with the X Stop interspinous implant: 1-year results. Eur Spine J 13:22-31, 2004

\section{Disclosure}

Roberto Gazzeri, Marcelo Galarza, Claudio Fiore, Andrea Faiola, Fabrizio Puzzilli, Giorgio Callovini, and Alex Alfieri report no conflict of interest concerning the materials and methods used in this study or the findings specified in this paper. Massimiliano Neroni has royalties from Sintea Plustek.

\section{Author Contributions}

Conception and design: Gazzeri, Galarza, Alfieri. Acquisition of data: all authors. Analysis and interpretation of data: Gazzeri, Neroni, Fiore, Callovini. Critically revising the article: Galarza, Alfieri. Approved the final version of the manuscript on behalf of all authors: Gazzeri. Administrative/technical/material support: Neroni, Fiore. Study supervision: Gazzeri.

\section{Correspondence}

Roberto Gazzeri, Department of Neurosurgery, San Giovanni Addolorata Hospital, Via Amba Aradam 9, Rome 00184, Italy. email: robertogazzeri@gmail.com. 